.

\title{
Forced Convection Boiling and Critical Heat Flux of Ethanol in Electrically Heated Tube Tests
}

Michael L. Meyer and Diane L. Linne

Lewis Research Center, Cleveland, Ohio

Donald C. Rousar

Aerojet Gencorp, Sacramento, California

Prepared for the

36th Aerospace Sciences Meeting \& Exhibit

sponsored by the American Institute of Aeronautics and Astronautics

Reno, Nevada, January 12-15, 1998

National Aeronautics and

Space Administration

Lewis Research Center 
Available from

NASA Center for Aerospace Information 800 Elkridge Landing Road

Linthicum Heights, MD 21090-2934

Price Code: A03
National Technical Information Service 5287 Port Royal Road Springfield, VA 22100 Price Code: $\mathrm{A} 03$ 


\title{
FORCED CONVECTION BOILING AND CRITICAL HEAT FLUX OF ETHANOL IN ELECTRICALLY HEATED TUBE TESTS
}

\author{
Michael L. Meyer and Diane L. Linne \\ National Aeronautics and Space Administration \\ Lewis Research Center \\ Cleveland, Ohio 44135 \\ and \\ Donald C. Rousar \\ Aerojet Gencorp \\ Sacramento, California
}

\begin{abstract}
Electrically heated tube tests were conducted to characterize the critical heat flux (transition from nucleate to film boiling) of subcritical ethanol flowing at conditions relevant to the design of a regeneratively cooled rocket engine thrust chamber. The coolant was SDA-3C alcohol (95 percent ethyl alcohol, 5 percent isopropyl alcohol by weight), and tests were conducted over the following ranges of conditions: pressure from 144 to 703 psia, flow velocities from 9.7 to $77 \mathrm{ft} / \mathrm{s}$, coolant subcooling from 33 to $362^{\circ} \mathrm{F}$, and critical heat fluxes up to $8.7 \mathrm{BTU} /$ in. $2 / \mathrm{sec}$. For the data taken near 200 psia, critical heat flux was correlated as a function of the product of velocity and fluid subcooling to within \pm 20 percent. For data taken at higher pressures, an additional pressure term is needed to correlate the critical heat flux. It was also shown that at the higher test pressures and/or flow rates, exceeding the critical heat flux did not result in wall burnout. This result may significantly increase the engine heat flux design envelope for higher pressure conditions.
\end{abstract}

\section{Introduction}

NASA is currently involved in a Space Shuttle upgrade program aimed at increasing the safety and reliability of the shuttle system while reducing the operations and maintenance costs. A major component of this upgrade program is to modify the Orbital Maneuvering System (OMS) and Reaction Control System (RCS) to operate with nontoxic propellants. ${ }^{1}$
The OMS engine is a 6000 lbf thrust, pressure-fed engine with a regeneratively-cooled combustion chamber. Operating chamber pressure is approximately 140 psia. Nitrogen tetroxide and monomethyl-hydrazine are used in the OMS engines for orbit insertion, circularization, and deorbit. These hypergolic propellants complicate ground and flight operations due to their toxic and corrosive nature. A proposed alternative propellant combination is liquid oxygen and ethanol.

Before replacing the current fuel with ethanol, the cooling characteristics of ethanol must be determined. Ethanol must be able to cool the chamber as well as, or better than, the monomethyl-hydrazine currently used. Except for a limited amount of data at heat fluxes lower than those expected in the OMS engine, ${ }^{2}$ no cooling data exists for ethanol. Because the ethanol will be subcritical in the coolant passages, it is necessary to determine the critical heat flux at which the ethanol will transition to the film-boiling regime, where wall temperatures can increase rapidly and coolant passage burn-out can occur.

Previous studies of critical heat flux for fluids at high velocity and subcooling conditions have been conducted during the past 40 years using electrically heated tubes. An evaluation of the data from these programs showed that the product of local velocity and local subcooling $\left(\mathrm{V} \Delta \mathrm{T}_{\mathrm{SUB}}\right)$ is a good correlating parameter for critical heat flux. Two regimes were often observed, a high $\mathrm{V} \Delta \mathrm{T}_{\text {SUB }}$ region ( $>2000$ to $5000^{\circ} \mathrm{F}-\mathrm{ft} / \mathrm{sec}$ ) and a low $\mathrm{V} \Delta \mathrm{T}_{\mathrm{SUB}}$ region. Most of the previous data correlation work focused on the high

Copyright $\Theta$ by the American Institute of Aeronautics and Astronautics, Inc. No copyright is asserted in the United States under Title 17, U.S Code. The U.S. Government has a royalty-free license to exercise all rights under the copyright claimed herein for Governmental Purposes. All other rights are reserved by the copyright owner. 
$\mathrm{V} \triangle \mathrm{T}_{\text {SUB }}$ region where the correlation was shown to be linear. Correlations for water, $\mathrm{N}_{2} \mathrm{H}_{4}$, Aerozine-50, $\mathrm{N}_{2} \mathrm{O}_{4}$ and $\mathrm{NH}_{3}$ are presented in references 3 and 4 . Correlations of this type were used to design regeneratively cooled thrust chambers for the Titan first and second stage engines (Aerozine-50 cooled), and the Space Shuttle OMS engine (MMH cooled).

The objective of the present investigation was to experimentally determine the critical heat flux (CHF) at which flowing ethanol coolant will transition from nucleate boiling to film boiling. Electrically heated tube tests were conducted for flow velocities ranging from 9.7 to $77 \mathrm{ft} / \mathrm{s}$, pressures ranging from 144 to $703 \mathrm{psia}$, and coolant subcooling from 33 to $362^{\circ} \mathrm{F}$. The critical heat flux results were then evaluated with two empirical correlations.

\section{Test Facility, Hardware, and Procedure}

Tests were conducted in the NASA Lewis Research Center Heated Tube Facility. This facility was developed
AIAA-98-1055

for simulating the heat flux conditions of a regeneratively cooled liquid rocket engine combustion chamber and is described in detail in reference 5 . The components used for the present study are briefly reviewed here.

\section{Facility}

A simplified schematic of the combustible liquids system is shown in figure 1 . The test section was mounted vertically within a vacuum chamber that was kept below $0.01 \mathrm{psi}(69 \mathrm{~Pa})$. The vacuum environment minimized heat losses due to convection and provided a measure of safety in the event of a fuel leak. The test section was heated electrically by passing a current through the tube using a $2000 \mathrm{amp}, 75 \mathrm{~V}$ DC power supply. The coolant fuel was stored in a supply tank rated for pressures up to $1650 \mathrm{psi}$. Separate valves were used for flow rate and test section back pressure control. For this test series, the control valves were pneumatically actuated and their size could be easily adjusted to accommodate the range of flow rates and back pressures. Two Coriolis-force flow meters

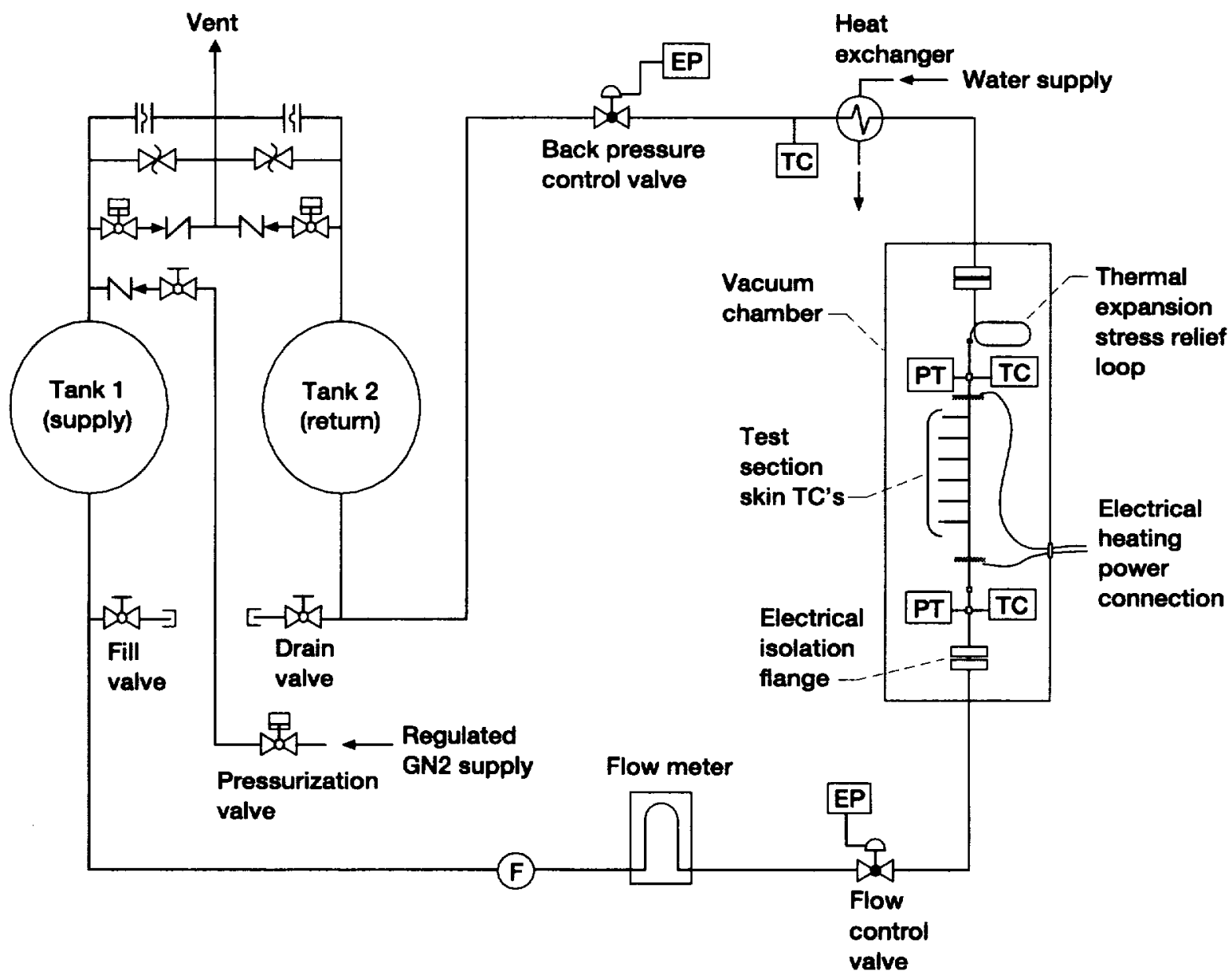

Figure 1.-Simplified schematic of the Heated Tube Facility's combustible liquids system (EP - electric to pneumatic, PT - pressure transducer, TC - thermocouple, F - filter). 
were used to provide accurate flow measurement of the ethanol fuel. One flow meter covered the range from 0 to $0.0833 \mathrm{lbm} / \mathrm{s}$. The second flow meter covered the range from 0 to $0.25 \mathrm{lbm} / \mathrm{s}$, and was used for tests with a flow rate greater than $0.0833 \mathrm{lbm} / \mathrm{s}$. The coolant temperature and pressure were measured at the inlet and exit of the test section, and heat input was determined by recording the voltage and current applied to the test section. Each of the facility and research instrumentation was recorded on the facility's data system at a rate of one complete cycle per second.

\section{Test Hardware}

The test sections for these experiments were fabricated from $0.125 \mathrm{in}$. outside diameter by $0.016 \mathrm{in}$. wall tubes of 304 stainless steel. The total test section length was 30 in. and was connected to 0.25 in. tubing at the inlet. Of the total length, $2.5,5.5$, or 19.5 in. were heated electrically. By varying the heated length, the coolant bulk temperature could be varied at a given velocity. A length of 6.5 in. $(\mathrm{LD}=70$ ) was provided before the start of the heated section to allow for flow development. For tests with high flow rate and short heated lengths, the unheated downstream portion of the 0.125 in. tube was replaced with a 0.25 in. outside diameter tube to minimize pressure drop. Copper disks of 0.5 in. thickness were brazed to the tube in a vacuum furnace braze process. The copper disks provided convenient electrical connections for heating.

The test sections were instrumented with type $K$ thermocouples spot welded directly to the outer surface of the tube. There were 4,6 , and 8 thermocouples on the 2.5 , 5.5 , and 19.5 in. test sections respectively. On the 2.5 in. test section, the thermocouples were placed one every 0.5 in. The 5.5 and 19.5 in. test sections were more heavily instrumented near the end of the test section where transition was expected. Figure 2 shows a typical arrangement of thermocouples for a 19.5 in. heated section. Each test section was calibrated in a water cooled calibration rig prior to testing to check and correct for induced temperature error caused by the voltage in the tube. Reference 6 discusses this error potential and the method used to correct for it if present.

\section{Procedure}

A typical test run started by filling the supply tank with ethanol and pressurizing the ullage with gaseous nitrogen. The empty return tank was vented to the atmosphere. The coolant flow was stabilized at flow rate and back pressure set points prior to turning on the electrical heating power supplies. The power was increased in steps until the heat flux approached a predicted value of
AIAA-98-1055

critical heat flux. The predicted $\mathrm{CHF}$ was determined by extrapolating the data of reference 2 . As data were collected, they were used to improve the prediction. Within about 30 percent of the predicted $\mathrm{CHF}$, power was increased slowly, with a pause at each new level to confirm that wall

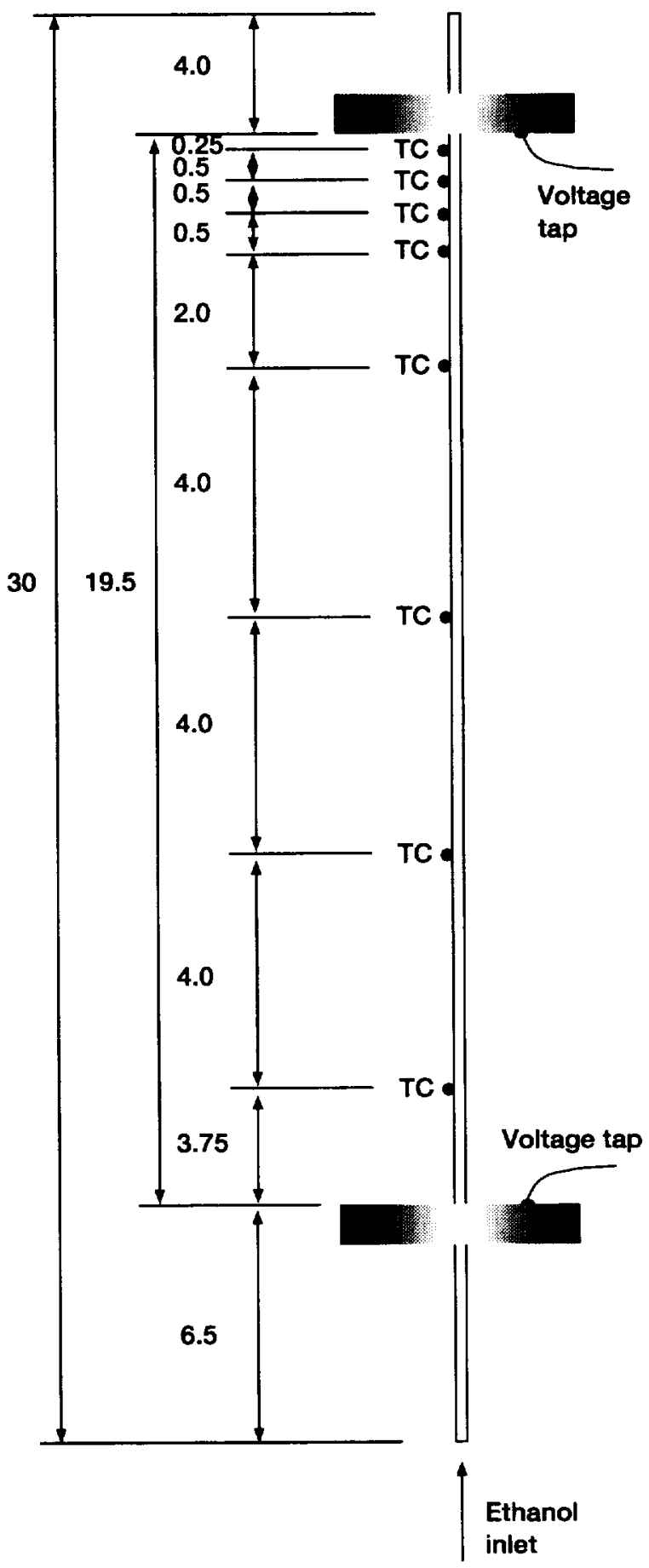

Figure 2.-Schematic of test section hardware and instrumentation. Dimensions are in inches. (TC - thermocouple). 
AIAA-98-1055

temperatures were still stable. When the experimental critical heat flux was reached, the temperature at one thermocouple (usually at the end of the tube) showed a sharp increase in tube wall temperature. This increase occurred within the one second data collection rate of the system, and was $1000^{\circ} \mathrm{F}$ or larger in magnitude. The sharp increase in tube wall temperature indicated the drastic reduction in heat transfer coefficient of the fluid as it transitioned to film boiling. Power was lowered as soon as one thermocouple indicated transition, usually before tube failure. For several tests, however, the runaway temperatures caused tube failure before power could be lowered. Figure 3 shows the profiles of fluid outlet temperature, heat flux, and coolant-side wall temperature versus test time for a representative test. The increase in local heat flux after CHF is exceeded is due to an increase of the tube resistance at high temperatures. Only the local heat flux near the hot spot increases; the average heat flux for the tube remains relatively constant. After the test, the ethanol that was collected in the return tank was pumped back into the supply tank for the next test.

Coolant side wall temperature was calculated from the hot side wall thermocouples using two methods. The first method was an iterative procedure that calculated local heat flux, electrical resistivity, and thermal conductivity for each tube portion containing a thermocouple. The second method used direct radial conduction assuming equal power distribution throughout the tube. Coolant wall temperatures calculated from the two methods were within one degree of each other. The temperature delta across the wall for the 304 SS ranged from $40^{\circ} \mathrm{F}$ at a heat flux of $1.2 \mathrm{BTU} / \mathrm{in} .{ }^{2} / \mathrm{sec}$ to $250^{\circ} \mathrm{F}$ at a heat flux of $9.0 \mathrm{BTU} / \mathrm{in} .{ }^{2} / \mathrm{sec}$. Coolant fluid temperature was calculated at each thermocouple based on incremental heat flux and fluid specific heat. The calculated value for the end of the heated section compared well with the measured fluid outlet temperature, indicating an energy balance for the tests.

\section{Coolant Properties}

Ethyl alcohol denatured with 5 percent isopropyl alcohol by weight (SDA-3C Ethanol) was used for these tests as defined by the Shuttle OMS/RCS upgrade program. Because even small mole fraction mixtures can significantly affect the boiling characteristics of the coolant, it was important to use the exact ethanol specified by the program for these tests. ${ }^{7}$ However, thermophysical properties were not available for this specific fuel blend. In lieu of properties for the exact fuel tested, properties for similar coolants as indicated in table I were used for the data reduction. Some important properties of ethyl alcohol and isopropyl alcohol are compared in table II. It is not expected that the differences in properties would significantly affect the results of the data reduction.

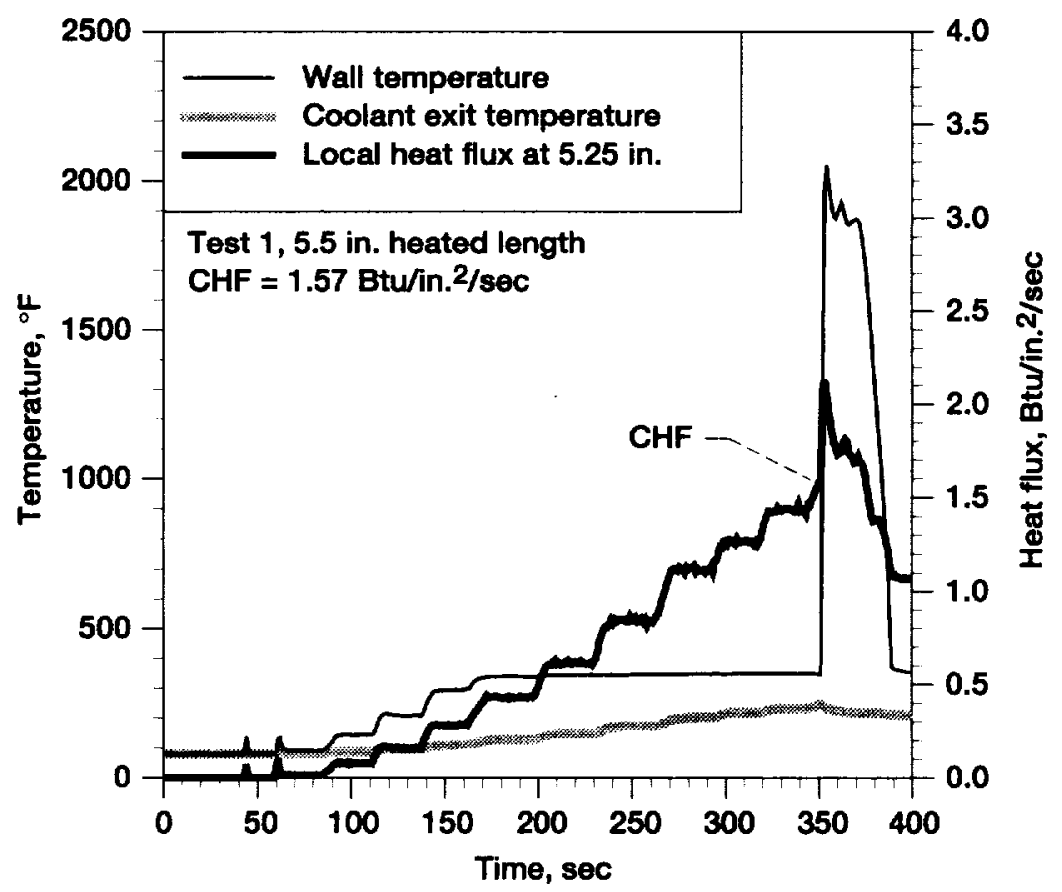

Figure 3.-Typical temperature and heat flux profiles during a test. 
Table I. Coolant Properties Used for Analysis

\begin{tabular}{|l|c|c|}
\hline \multicolumn{1}{|c|}{ Property } & Fluid for obtaining property & Reference \\
\hline Density, Viscosity & 96 percent Ethanol, 4 percent Water & 8 \\
\hline Enthalpy, Thermal Conductivity & 100 percent Ethanol & 8 \\
\hline Specific Heat & 100 percent Ethanol & 9 \\
\hline
\end{tabular}

Table II. Comparison of Alcohol Properties

\begin{tabular}{|l|c|c|}
\hline \multicolumn{1}{|c|}{ Property } & Ethyl alcohol & Isopropyl alcohol \\
\hline Critical Pressure, psia & 927 & 779 \\
\hline Critical Temperature, ${ }^{\circ} \mathrm{F}$ & 470 & 456 \\
\hline Specific Gravity at $68^{\circ} \mathrm{F}$ & 0.791 & 0.786 \\
\hline Specific Heat at $68^{\circ} \mathrm{F}, \mathrm{BTU} / \mathrm{lbm} /{ }^{\circ} \mathrm{F}$ & 0.572 & 0.600 \\
\hline
\end{tabular}

On site chemical analysis verified that the delivered SDA-3C agreed with the manufacturer specifications for ethanol and isopropanol content. However, the alcohol did contain approximately 0.5 percent water by weight. Periodic samples were also collected and analyzed to verify that the composition of the coolant did not degrade during testing. Therefore, reuse of the fuel was validated.

\section{Results and Discussion}

The objective of this investigation was to determine the critical heat flux (CHF) at which flowing ethanol coolant will transition from nucleate boiling to film boiling. Because exceeding the CHF can result in tube failure, it is considered the limiting heat flux for design of an engine. A wide range of flow rate, pressure, bulk temperature, and heat flux conditions representative of the conditions in a regeneratively cooled OMS engine cooling passage were tested. The test conditions and results are summarized in table III.

A plot of heat flux versus inside tube wall temperature for a typical test is provided in figure 4. At low heat fluxes, the heat transfer mechanism is forced convection, and the wall temperature rises proportionally with heat flux. As heat flux continues to increase, the curve steepens due to a transition to nucleate boiling. In this regime, the heat transfer coefficient increases dramatically, allowing wall temperatures to remain relatively constant. At the CHF, the wall begins to dry out, and a large wall temperature excursion occurs because the vapor layer on the wall significantly reduces the heat transfer coefficient. As was discussed previously, the large temperature rise and corresponding increase in tube resistance cause the local heat flux to increase as CHF is exceeded.

\section{CHF Correlation}

Several empirical and semi-empirical methods were evaluated for correlating critical heat flux in a flowing liquid in recent review articles. ${ }^{10.11}$ For the present investigation, the product of flow velocity and subcooling $\left(\mathrm{V} \times\left(\mathrm{T}_{\mathrm{SAT}}-\mathrm{T}_{\text {BULK}}\right)\right.$ ) was selected as the correlating parameter because it has been successfully used to correlate CHF data for other fuels as well as water. ${ }^{3,4}$ Figure 5 plots critical heat flux versus $V \Delta T_{S U B}$ for heated section exit pressures near $200 \mathrm{psia}$. The CHF has been correlated with the following equation:

$$
\mathrm{CHF}=0.1003+0.05264 \cdot \sqrt{\mathrm{V} \Delta \mathrm{T}_{\text {SUB }}}
$$

where CHF is in $B T U / \mathrm{in}^{2} / \mathrm{sec}$ and $\mathrm{V} \Delta \mathrm{T}_{\mathrm{SUB}}$ is in ${ }^{\circ} \mathrm{F}$-ft/s. Equation (1) correlates CHF to within \pm 20 percent. The data of reference 2 are also plotted in figure 5 and are in good agreement with the present results. The data in reference 2 were obtained for pure ethanol in a larger diameter tube ( $0.39 \mathrm{in}$. inside diameter) and at 29 and 181 psia. The agreement of the data suggests that the presence of 5 percent isopropyl alcohol has little impact on the test results at these pressures. While the difference in tube diameter between these two data sets was not expected to impact the results, CHF may vary if tubes much smaller than those of the present investigation were used. ${ }^{12}$

In the tests conducted at pressures above $250 \mathrm{psia}$ or pressures less than 250 psia and flow velocities greater than $60 \mathrm{ft} / \mathrm{sec}$, a number of differences from the cooling behavior in figure 4 occurred as shown in figure 6 . In these cases, a smaller temperature excursion $\left(50\right.$ to $\left.200^{\circ} \mathrm{F}\right)$ indicated transition from nucleate boiling to an alternate 
AIAA-98-1055

Table III. Summary of Test Conditions and Results

\begin{tabular}{|c|c|c|c|c|c|c|c|c|c|}
\hline $\begin{array}{c}\text { Test } \\
\#\end{array}$ & $\begin{array}{c}\text { Test } \\
\text { section \# }\end{array}$ & $\begin{array}{l}\text { Heated } \\
\text { length } \\
\text { (in.) }\end{array}$ & $\begin{array}{l}\text { Pressure } \\
\text { (psia)* }\end{array}$ & $\begin{array}{l}\mathrm{T}_{\text {bulk }} \\
\left({ }^{\circ} \mathrm{F}\right)^{*}\end{array}$ & $\begin{array}{l}\text { Velocity } \\
(\mathrm{ft} / \mathrm{sec})^{*}\end{array}$ & $\begin{array}{l}\text { Flow rate } \\
(\mathrm{lbm} / \mathrm{sec})\end{array}$ & $\begin{array}{c}\mathrm{T}_{\mathrm{SAT}} \\
\left({ }^{\circ} \mathrm{F}\right)^{*}\end{array}$ & $\begin{array}{c}\mathrm{V} \Delta \mathrm{T}_{\text {SUB }} \\
\mathrm{EXP} \\
\left({ }^{\circ} \mathrm{F}-\mathrm{ft} / \mathrm{s}\right)^{*}\end{array}$ & $\begin{array}{c}\text { CHF EXP } \\
\text { (BTU/in. }{ }^{2} / \mathrm{s} \text { ) }\end{array}$ \\
\hline 1 & 1 & 5.50 & 206 & 249 & 9.7 & 0.0204 & 332 & 825 & 1.57 \\
\hline 2 & 1 & 5.50 & 222 & 256 & 15.8 & 0.0329 & 338 & 1348 & 2.28 \\
\hline 3 & 2 & 5.50 & 219 & 225 & 21.2 & 0.0459 & 337 & 2622 & 2.62 \\
\hline 4 & 3 & 19.58 & 214 & 317 & 20.5 & 0.0404 & 335 & 796 & 1.21 \\
\hline 5 & 3 & 19.58 & 221 & 317 & 28.2 & 0.0553 & 338 & 1010 & 1.64 \\
\hline 6 & 8 & 19.50 & 204 & 296 & 48.1 & 0.0966 & 332 & 2304 & 2.94 \\
\hline 7 & 6 & 5.52 & 199 & 209 & 28.2 & 0.0615 & 330 & 3585 & 3.31 \\
\hline 8 & 7 & 5.56 & 224 & 180 & 56.8 & 0.1267 & 339 & 9395 & 5.47 \\
\hline 9 & 4 & 2.48 & 204 & 185 & 9.9 & 0.0220 & 331 & 1484 & 1.78 \\
\hline 10 & 4 & 2.48 & 214 & 153 & 19.5 & 0.0441 & 335 & 3585 & 2.88 \\
\hline 11 & 5 & 2.50 & 259 & 133 & 39.4 & 0.0904 & 351 & 8679 & 4.37 \\
\hline 12 & 10 & 2.50 & 223 & 116 & 74.1 & 0.1737 & 339 & 18340 & 6.99 \\
\hline 13 & 9 & 2.47 & 555 & 118 & 36.6 & 0.0870 & 420 & 12600 & 3.97 \\
\hline 14 & 10 & 2.50 & 531 & 126 & 55.0 & 0.1302 & 415 & 18390 & 6.11 \\
\hline 15 & 10 & 2.50 & 514 & 135 & 73.8 & 0.1741 & 411 & 24230 & 8.67 \\
\hline 16 & 7 & 5.56 & 220 & 223 & 15.3 & 0.0329 & 337 & 1797 & 2.25 \\
\hline 17 & 7 & 5.56 & 228 & 228 & 20.5 & 0.0439 & 340 & 2408 & 2.98 \\
\hline 18 & 8 & 19.50 & 202 & 288 & 62.4 & 0.1260 & 331 & 3309 & 3.69 \\
\hline 19 & 8 & 19.50 & 205 & 304 & 28.2 & 0.0560 & 332 & 1145 & 1.76 \\
\hline 20 & 8 & 19.50 & 202 & 309 & 20.2 & 0.0398 & 331 & 667 & 1.28 \\
\hline 21 & 9 & 2.47 & 365 & 134 & 36.6 & 0.0866 & 380 & 10900 & 4.75 \\
\hline 22 & 9 & 2.47 & 218 & 144 & 38.3 & 0.0872 & 337 & 7483 & 5.40 \\
\hline 23 & 10 & 2.50 & 514 & 125 & 37.0 & 0.0876 & 411 & 12290 & 4.17 \\
\hline 24 & 10 & 2.50 & 209 & 115 & 63.4 & 0.1497 & 334 & 16190 & 6.43 \\
\hline 25 & 10 & 2.50 & 211 & 111 & 73.3 & 0.1735 & 334 & 19160 & 7.08 \\
\hline 26 & 10 & 2.50 & 471 & 118 & 36.7 & 0.0872 & 403 & 12110 & 4.03 \\
\hline 27 & 10 & 2.50 & 336 & 71 & 38.2 & 0.0908 & 373 & 11500 & 4.54 \\
\hline 28 & 10 & 2.50 & 280 & 120 & 39.0 & 0.0902 & 358 & 9291 & 4.53 \\
\hline 29 & 10 & 2.50 & 299 & 68 & 54.4 & 0.1298 & 368 & 16310 & 5.53 \\
\hline 30 & 10 & 2.50 & 299 & 72 & 21.3 & 0.0506 & 363 & 6183 & 2.96 \\
\hline 31 & 12 & 5.50 & 319 & 159 & 76.7 & 0.1742 & 368 & 20740 & 7.55 \\
\hline 32 & 12 & 5.50 & 297 & 209 & 23.2 & 0.0504 & 362 & 3553 & 3.52 \\
\hline 33 & 11 & 2.50 & 703 & 109 & 32.0 & 0.0747 & 442 & 10720 & 3.18 \\
\hline 34 & 11 & 2.50 & 606 & 66 & 35.5 & 0.0850 & 427 & 12850 & 3.84 \\
\hline 35 & 11 & 2.50 & 167 & 108 & 56.2 & 0.1306 & 316 & 11670 & 5.87 \\
\hline 36 & 11 & 2.50 & 144 & 106 & 58.0 & 0.1349 & 305 & 11530 & 6.06 \\
\hline 37 & 4 & 2.48 & 233 & 141 & 29.6 & 0.0675 & 342 & 5954 & 3.74 \\
\hline 38 & 7 & 5.56 & 208 & 192 & 37.2 & 0.0821 & 333 & 5458 & 4.28 \\
\hline
\end{tabular}

* Calculated at location of transition from nucleate to film boiling. 


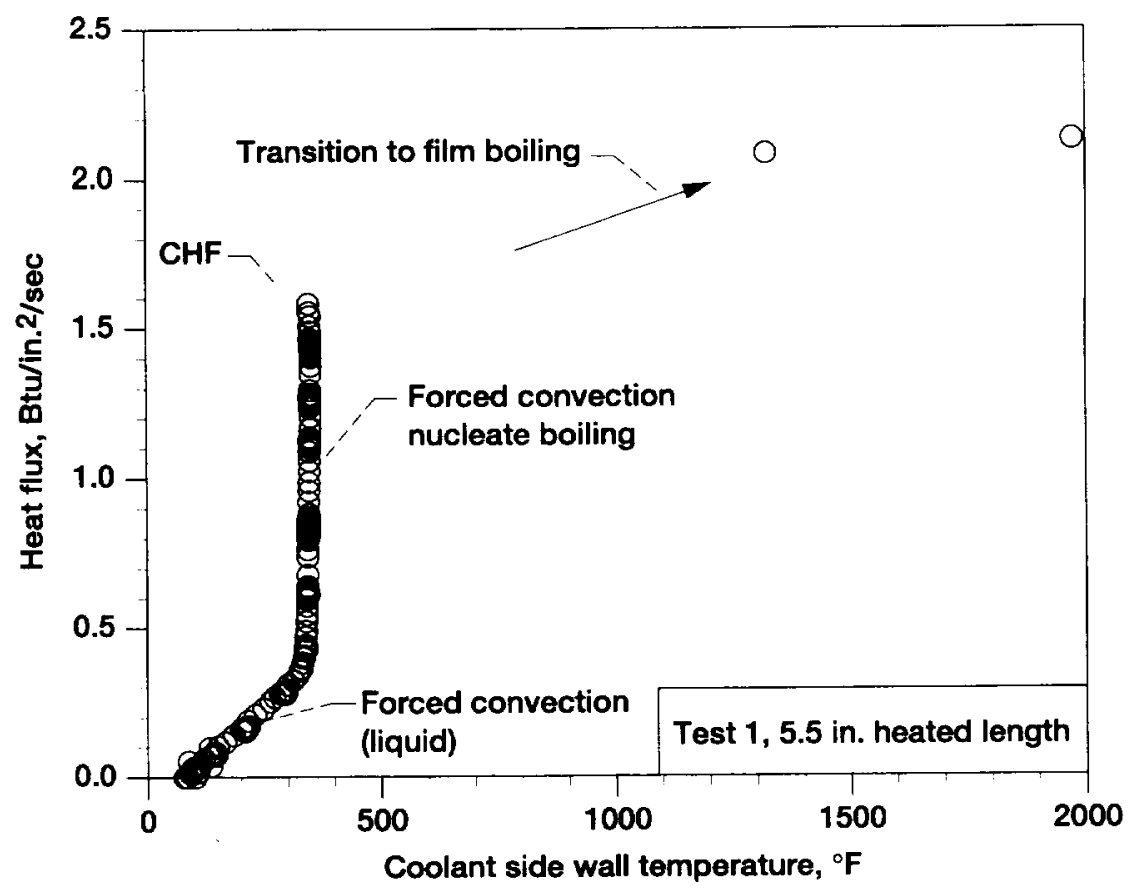

Figure 4.-Typical heat flux vs. wall temperature plot showing the changing modes of heat transfer with increasing heat flux.

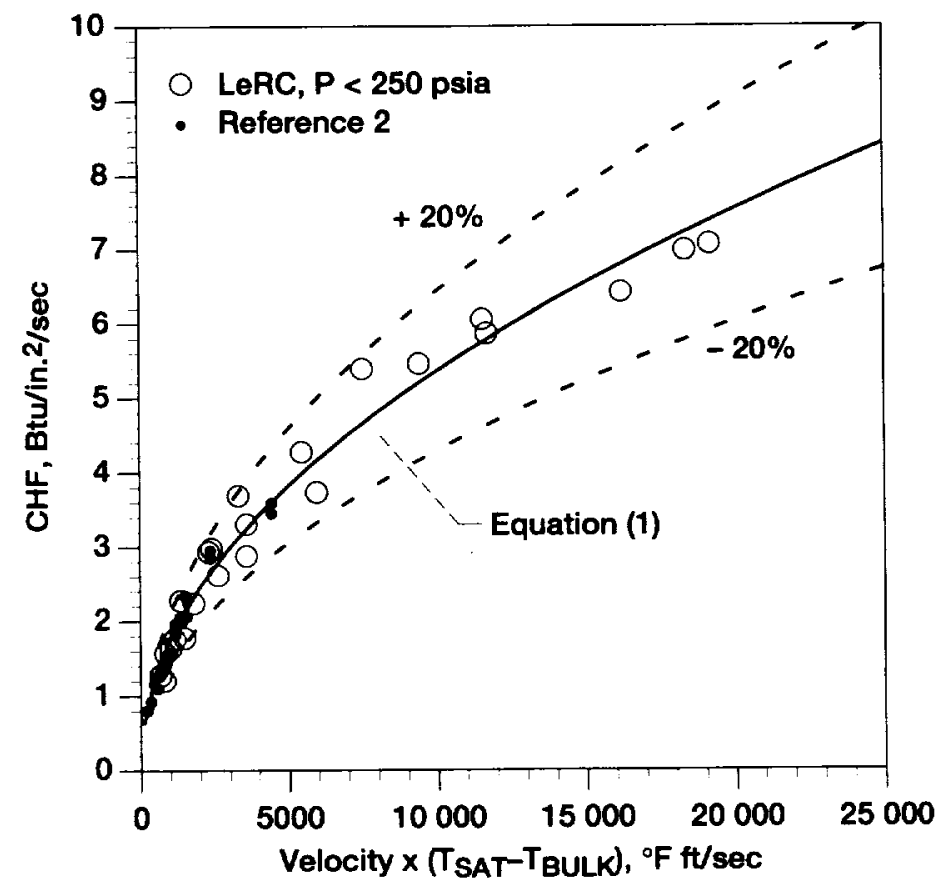

Figure 5.-Present ethanol critical heat flux data compared to data of reference 2. 


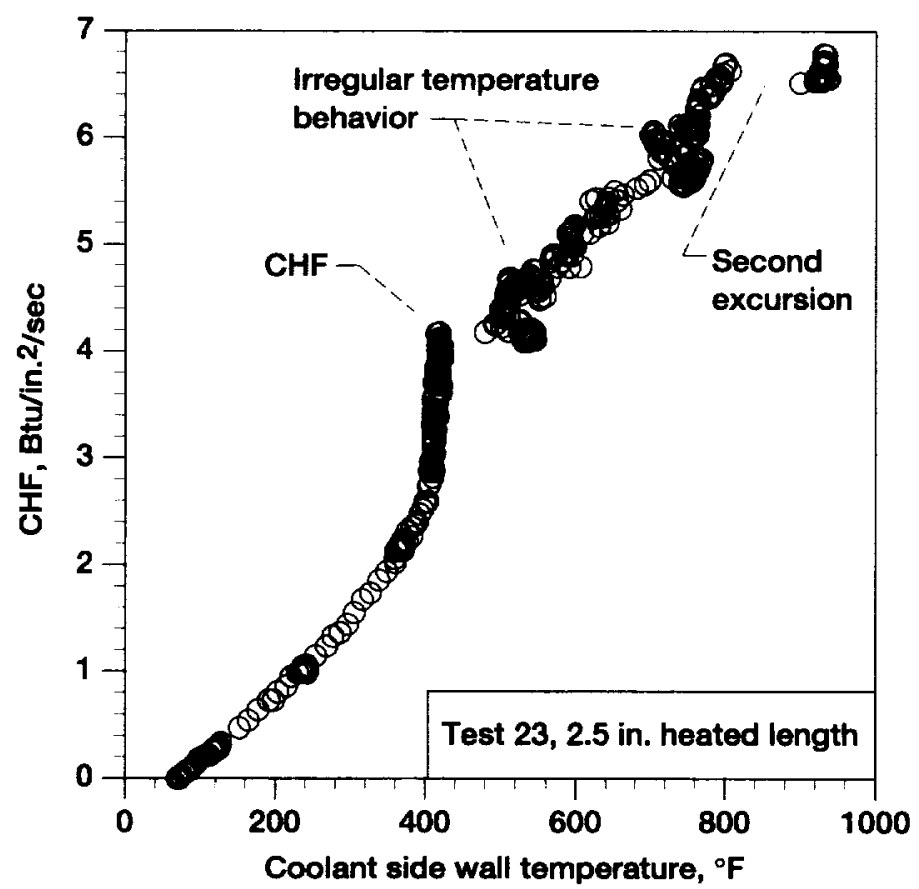

AIAA-98-1055

Figure 6.-Typical heat flux vs. wall temperature behavior for high pressure tests.

cooling mechanism. The heat flux at this transition was defined as the critical heat flux for these tests, although the alternate cooling mechanism did not appear to be true film boiling. Increasing heat flux beyond the CHF resulted in a period of irregular but steadily increasing wall temperatures. It is possible that this is a transitional cooling mechanism because a heat flux was eventually reached where a second temperature excursion would occur. There were also several other differences from the low pressure tests. Whereas the transition to film boiling at lower pressures typically occurred near the exit of the heated test section, in these cases the transition often occurred at an upstream thermocouple station. This type of behavior at high pressure and high flow rates was also noted in tests discussed in reference 11 with water and R-12, but no cause was determined. Another unusual phenomenon in the present tests was the onset of high pitched sounds emanating from the test chamber simultaneous with the first, small, temperature excursion. These sounds generally continued at increased heat fluxes.

The CHF data of figure 5 are replotted in figure 7 along with data collected at higher pressures. The data indicate that the CHF decreases with increasing pressure. This decrease in CHF may in part be due to the pressure dependence of the correlating parameter $\mathrm{V} \Delta \mathrm{T}_{\mathrm{SUB}}$. However, since pure fluids do not typically exhibit this pressure dependence, it may also be due to mixture effects for the SDA-3C ethanol. Some pressure dependence has been observed for other mixtures, but the cause has not been investigated.

In order to develop a design correlation that is independent of pressure, the ratio of $\mathrm{CHF}$ to $\mathrm{CHF}$ at 200 psia was plotted versus pressure in figure 8 for a relatively constant $\mathrm{V} \Delta \mathrm{T}_{\text {SUB }}$. The data in this limited range of $V \Delta T_{S U B}$ suggest a linear relationship between $C H F$ and pressure, such that a correction factor can be proposed:

$$
\frac{\mathrm{CHF}(\mathrm{P})}{\mathrm{CHF}(200)}=\mathrm{F}_{\mathrm{P}}=1.17-8.56 \times 10^{-4} \cdot \mathrm{P}
$$

Thus, CHF at any pressure can be determined by modifying equation (1) with the factor $F_{P}$ as:

$$
\mathrm{CHF}=\mathrm{CHF}(200) \cdot \mathrm{F}_{\mathrm{P}}
$$

$P$ is the pressure in psia and $\mathrm{CHF}(200)$ is determined from equation (1). The experimental data are replotted in figure 9 with $\mathrm{CHF}$ corrected by $F_{P}$ for pressures different from 200 psia. Nearly all of the data now falls within \pm 20 percent of the curve fit calculated for 200 psia. However, the limited data taken at higher pressures and high and low $\mathrm{V} \Delta \mathrm{T}_{\text {SUB }}$ indicate that this relationship may not hold over the entire range of conditions tested. Further testing will be necessary to validate the design correlation for the entire range of test conditions. 
AIAA-98-1055

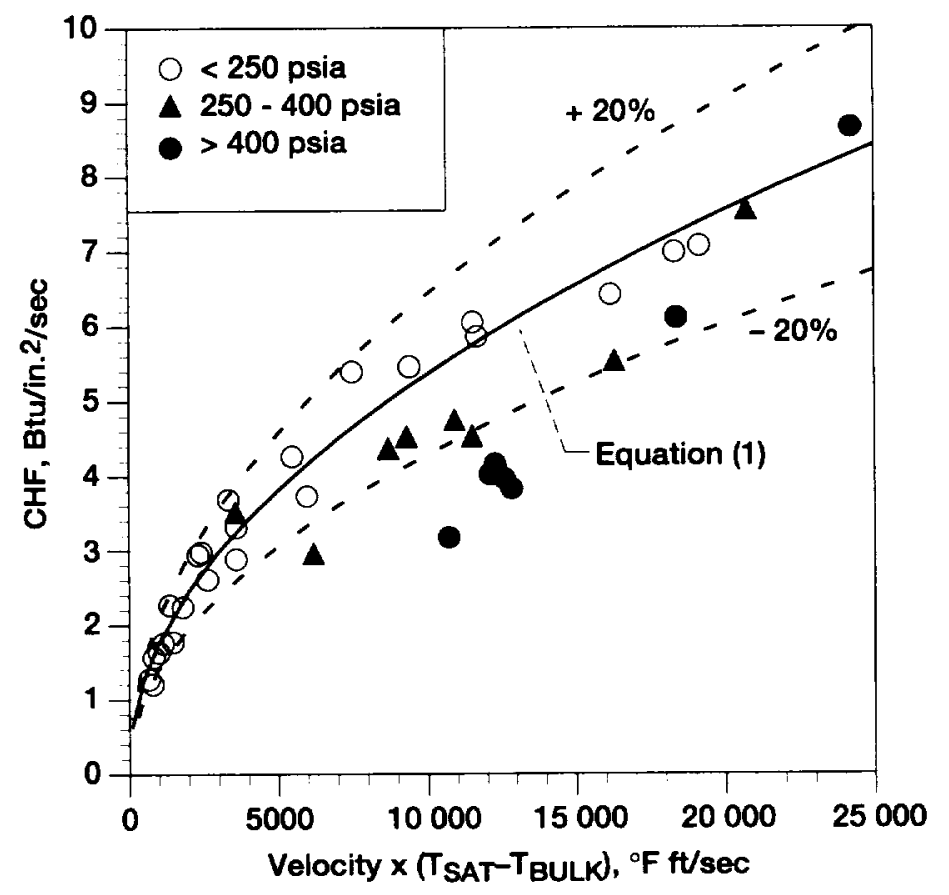

Figure 7.-Present ethanol critical heat flux data for various pressures compared to equation (1).

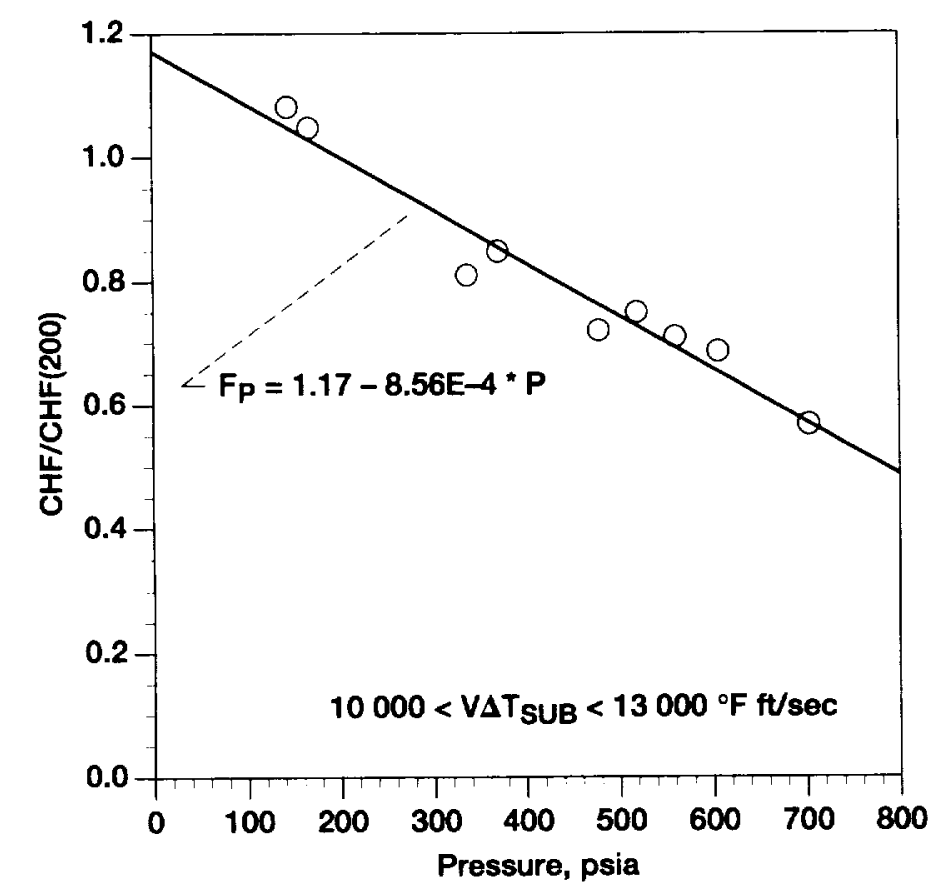

Figure 8.-The ratio of critical heat flux to the critical heat flux at $\mathbf{2 0 0}$ psia at a fixed $V \Delta T$ SUB plotted as a function of pressure. 


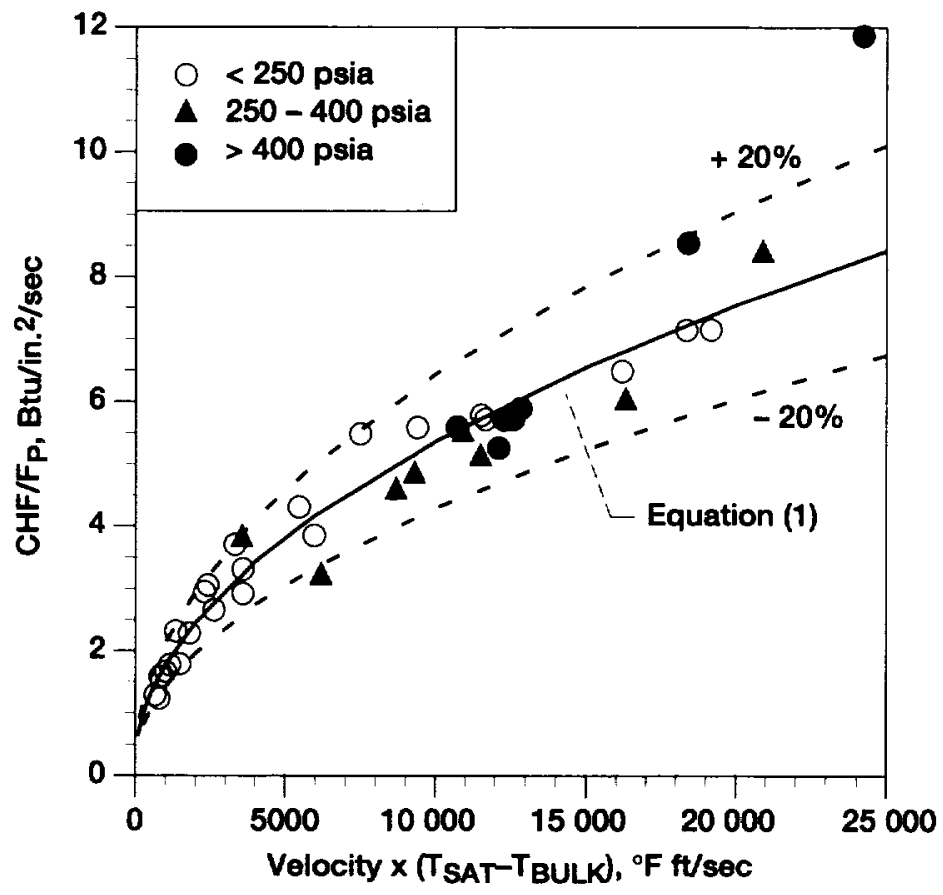

AIAA-98-1055

Figure 9.-Critical heat flux corrected to 200 psia pressure using $F_{P}$ and compared to equation (1).

While it is desirable to accurately predict $\mathrm{CHF}$ at the higher pressures, the heat transfer behavior exhibited in figure 6 indicates that it may not be critical from a design standpoint. Since the temperature remains relatively stable and within typical material structural limits above the $\mathrm{CHF}$, a cooling passage could be designed to exceed the CHF without risking burnout. Thus, the design limit for the maximum heat flux that can be cooled with the ethanol fuel can potentially be increased to give the designer greater flexibility.

\section{Modified Tong Correlation}

The literature was reviewed for other correlations that have been used in the past for critical heat flux in subcooled, boiling flows. Reference 10 conducted an extensive analysis of correlations to determine their usefulness in predicting $\mathrm{CHF}$ in water. The paper considered tens of known correlations, and selected four of the most promising for evaluation using 1865 experimental data points gathered from 25 sources. Of these four correlations, the modifiedTong correlation proved best, with 76 percent of its predictions within \pm 25 percent of the experimental data. This correlation can be written as follows:

$$
\mathrm{CHF}=\mathrm{Gh}_{\mathrm{fg}} \mathrm{C} / \operatorname{Re}^{0.5}
$$

where:
G mass flux (lbm/in $\left.{ }^{2}-\mathrm{s}\right)$

$\mathrm{h}_{\mathrm{fg}} \quad$ latent heat of vaporization (BTU/bm)

$\operatorname{Re}$ Reynolds number based on tube inside diameter

$$
\mathrm{C}=(0.216+0.0474 * \mathrm{P}) * \psi(\mathrm{P} \text { is in } \mathrm{MPa})
$$

$$
\begin{array}{ll}
\psi=0.825+0.986 * \mathrm{X}_{\mathrm{ex}} & \text { if } \mathrm{X}_{\mathrm{ex}}>-0.1 \\
\psi=1.0 & \text { if } \mathrm{X}_{\mathrm{ex}}<-0.1 \\
\psi=1.0 /\left(2+30 * \mathrm{X}_{\mathrm{ex}}\right) & \text { is } \mathrm{X}_{\mathrm{ex}}>0 \\
\mathrm{X}_{\mathrm{ex}}=\left(-\mathrm{C}_{\mathrm{p}}\right)^{*}\left(\mathrm{~T}_{\mathrm{SAT}}-\mathrm{T}_{\mathrm{BULK}}\right) / \mathrm{h}_{\mathrm{fg}} &
\end{array}
$$

The modified-Tong correlation was developed for a specified range of mass flux, pressure, tube inner diameter, fluid sub-cooling, heat flux, and tube $\mathrm{L} / \mathrm{D}$. The conditions in the current experiments all fall within the specified range for the modified-Tong correlation except for the tube $L / D$. The range recommended for the modified-Tong is between 12 and 40 . In these experiments, the $L D$ was 27,59 , and 210 . However, reference 10 indicates that the modified-Tong predicted experimental CHF well even outside of the range for which it was developed.

Using the modified-Tong correlation, critical heat fluxes were calculated for the conditions of the ethanol tests, and these predictions are compared in figure 10 to the experimental critical heat fluxes. The dotted line in the 
AIAA-98-1055

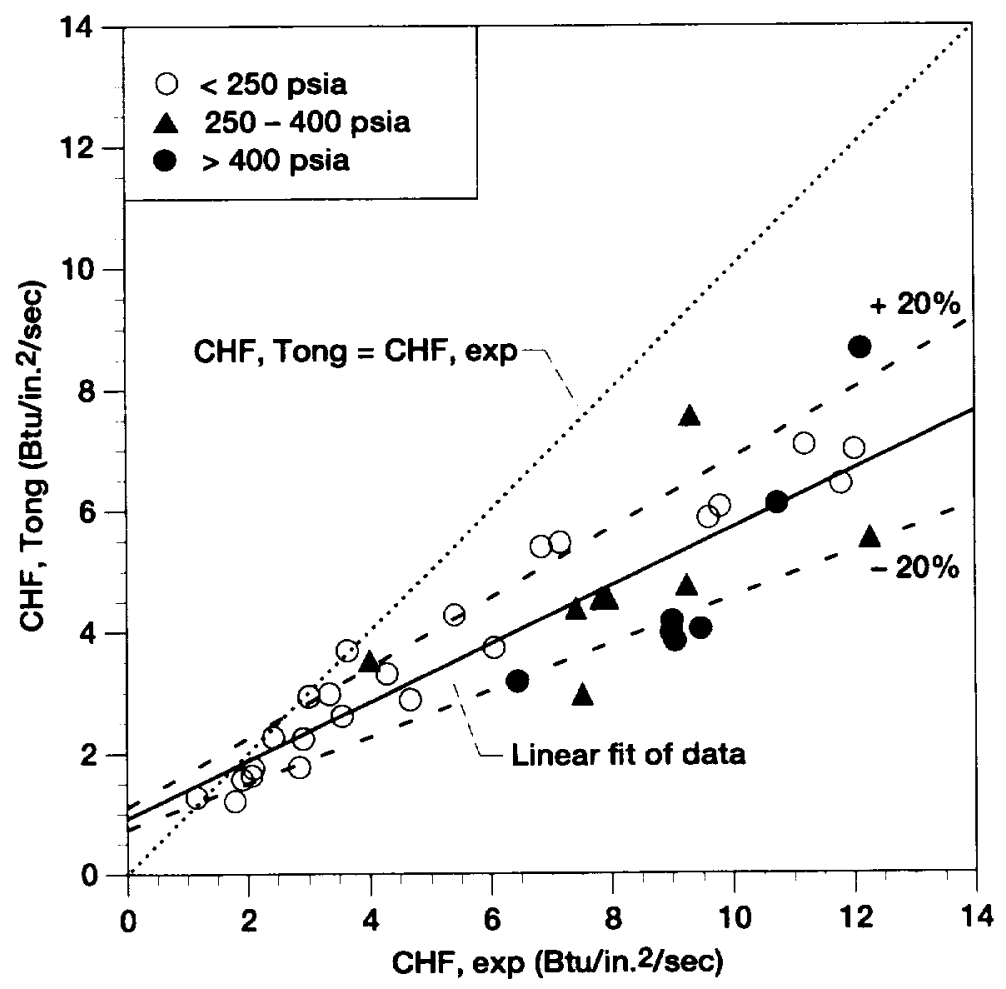

Figure 10.-Comparison of the modified-Tong correlation predictions to the experimental critical heat flux for ethanol.

figure shows the locus of agreement between the prediction and the experimental data. Nearly all of the data are greater than the prediction. Also shown in the figure is the best fit linear relationship (solid line) with \pm 20 percent bounds. It can be seen, however, that many of the experimental data lie outside of even the modified linear relationship, and that the modified-Tong does not model the data as well as the previous correlation based on velocity, sub-cooling, and pressure.

To determine if the failure of the modified-Tong correlation was due to the L/D being outside of the recommended range, the ratio of experimental CHF to modified-Tong CHF was plotted versus tube L/Din figure 11 . This figure shows that the correlation fits better at the highest LD values that were significantly outside of the original range of the modified-Tong. Therefore, the high $\mathrm{LD}$ is not considered to be the cause for the failure of the correlation to model the current experimental data.

\section{Conclusions}

Electrically heated tube experiments were conducted with subcritical ethyl alcohol (SDA-3C) to characterize the critical heat flux (CHF) of this coolant. The conditions tested were applicable to the design of a regeneratively cooled rocket engine thrust chamber. The results of the investigation led to the following conclusions.

1. CHF for ethanol (SDA-3C) has been characterized for a wide range of flow velocity and subcooling at 200 psia. The data falls within \pm 20 percent of the correlation provided using the product of velocity and subcooling ( $\left.\mathrm{V} \Delta \cdot \mathrm{T}_{\mathrm{SUB}}\right)$ as the correlating parameter. The data is in agreement with data from a previous study and significantly expands the operating conditions tested.

2. For data collected over a wider range of pressures (144 to 703 psia) an additional pressure factor was needed to correlate the data. Further testing will be required to validate this pressure factor for the full range of flow velocity and subcooling conditions tested.

3. The data at high pressure or lower pressure and high velocity indicate that exceeding CHF is not likely to cause burnout. Therefore, CHF may not be the limiting heat flux for design purposes at these conditions. 


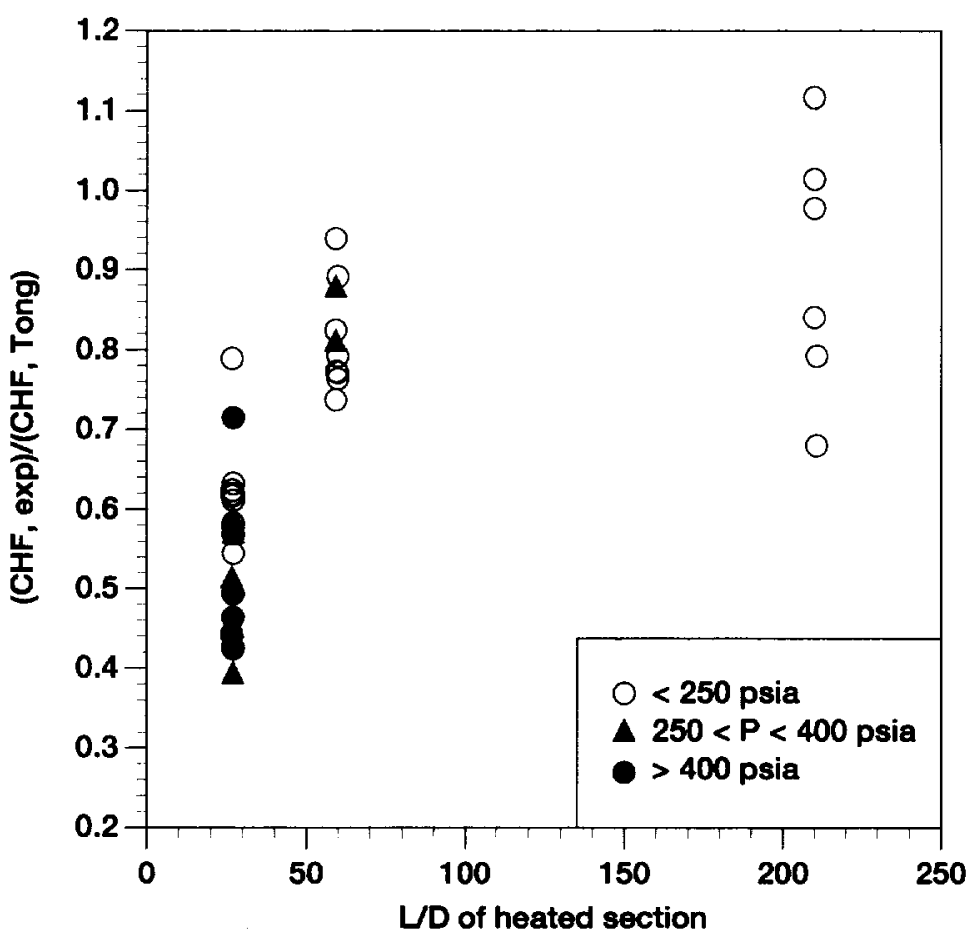

Figure 11.-The effect of tube length to diameter ratio on the comparison of the modified-Tong prediction to the experimental critical heat flux.

\section{References}

1. "Technology and Advanced Development for a NonToxic Orbital Maneuvering System and Reaction Control System for Orbiter Upgrade," NASA Research Announcement 9-NRA-BE-96-1, 1996.

2. Sterman, L.S., Mikhaylov, V.D., Vilemas, Yu., and Abramov, A.I., "Critical Heat Fluxes in Boiling Organic Heat-Transfer Media In Pipes and In a Pool," Proc. 2nd All-Soviet Union Conf. on Heat and Mass Transfer, 1964.

3. Rousar, D.C., "Correlation of Burnout Heat Flux for Fluids at High Velocity and High Subcooling Conditions," MS Thesis, University of California, Davis, 1966.

4. Greisen, D.A., and Rousar, D.C., "Critical Heat Flux Limits for High Velocity, High Subcooling Water Flows," AIAA-97-2912, presented at the 33rd AIAA/ASME/SAE/ASEE Joint Propulsion Conference and Exhibit, July 6-9, 1997.

5. Green, J.M., Pease, G.M., and Meyer, M.L., "A Heated Tube Facility for Rocket Coolant Channel Research," AIAA-95-2936, 1996.
6. Meyer, M.L., "Electrically Heated Tube Investigation of Cooling Channel Geometry Effects," AIAA95-2500, NASA TM-106985, 1995.

7. Shock, R.A.W., "Nucleate Boiling in Binary Mixtures," Int. J. Heat Mass Transfer, Vol. 20, pp. 701-709, 1977.

8. Vargaftik, N.B., Handbook of Physical Properties of Liquids and Gases, Second Edition, Hemisphere Publishing Corporation, 1983.

9. Touloukian, Y.S. and Makita, T., Specific Heat, Nonmetallic Liquids and Gases, IFI/Plenum, 1970.

10. Celata, G.P.,Cumo, M., and Mariani, A., “Assessment of Correlations and Models for the Prediction of CHF in Water Subcooled Flow Boiling," Int. J. Heat Mass Transfer, Vol. 37, No. 2, pp. 237-255, 1994.

11. Katto, Y., "Critical Heat Flux in Boiling," Proc. of the Eighth International Heat Transfer Conference, Vol. 1, pp. 171-180, 1986.

12. Ornatskii, A.P., Viniarskii, L.S., High Temperature, Vol. 3, No. 3, Soviet Union, 1965. 

Public reporting burden for this collection of information is estimated to average 1 hour per response, including the time for reviewing instructions, searching existing data sources, gathering and maintaining the data needed, and completing and reviewing the collection of information. Send comments regarding this burden estimate or any other aspect of this collection of information, including suggestions for reducing this burden, to Washington Headquarters Services, Directorate for information Operations and Reports, 1215 Jefferson Davis Highway, Suite 1204, Arlington, VA 22202-4302, and to the Office of Management and Budget, Paperwork Reduction Project (0704-0188), Washington, DC 20503.

\begin{tabular}{l|l|l}
\hline 1. AGENCY USE ONLY (Leave blank) & 2. REPORT DATE & 3. REPORT TYPE AND DATES COVERED
\end{tabular}

\section{TITLE AND SUBTITLE}

January 1998

Technical Memorandum

Forced Convection Boiling and Critical Heat Flux of Ethanol in Electrically Heated Tube Tests

\section{AUTHOR(S)}

Michael L. Meyer, Diane L. Linne, and Donald C. Rousar

\section{PERFORMING ORGANIZATION NAME(S) AND ADDRESS(ES)}

National Aeronautics and Space Administration

Lewis Research Center

Cleveland, Ohio 44135-3191
WU-523-61-13-00

\section{SPONSORINGMONITORING AGENCY NAME(S) AND ADDRESS(ES)}

National Aeronautics and Space Administration

Washington, DC 20546-0001
8. PERFORMING ORGANRATION REPORT NUMBER

E-11032

\section{SUPPLEMENTARY NOTES}

Prepared for the 36th Aerospace Sciences Meeting \& Exhibit sponsored by the American Institute of Aeronautics and Astronautics, Reno, Nevada, January 12-15, 1998. Michael L. Meyer and Diane L. Linne, NASA Lewis Research Center; Donald C. Rousar, Aerojet Gencorp, Sacramento, California. Responsible person, Michael L. Meyer, organization code 5830, (216) 977-7492.

12a. DISTAIBUTION/AVAILABILITY STATEMENT 12b. DISTRIBUTION CODE

Unclassified - Unlimited

Subject Categories: 20 and 28

Distribution: Nonstandard

This publication is available from the NASA Center for AeroSpace Information, (301) 621-0390.

\section{ABSTRACT (Maximum 200 mords)}

Electrically heated tube tests were conducted to characterize the critical heat flux (transition from nucleate to film boiling) of subcritical ethanol flowing at conditions relevant to the design of a regeneratively cooled rocket engine thrust chamber. The coolant was SDA-3C alcohol (95\% ethyl alcohol, $5 \%$ isopropyl alcohol by weight), and tests were conducted over the following ranges of conditions: pressure from 144 to 703 psia, flow velocities from 9.7 to $77 \mathrm{ft} / \mathrm{s}$, coolant subcooling from 33 to $362{ }^{\circ} \mathrm{F}$, and critical heat fluxes up to $8.7 \mathrm{BTU} / \mathrm{in} .{ }^{2} / \mathrm{sec}$. For the data taken near $200 \mathrm{psia}$, critical heat flux was correlated as a function of the product of velocity and fluid subcooling to within $\pm 20 \%$. For data taken at higher pressures, an additional pressure term is needed to correlate the critical heat flux. It was also shown that at the higher test pressures and/or flow rates, exceeding the critical heat flux did not result in wall burnout. This result may significantly increase the engine heat flux design envelope for higher pressure conditions.

\section{SUBJECT TERMS}

Ethanol; Heat transfer; Heated tubes; Critical heat flux; Boiling

17. SECUATYY CLASSIFICATION OF REPORT

Unclassified
18. SECURTY CLASSIFICATION OF THIS PAGE Unclassified
19. SECUAITY CLASSIFICATION OF ABSTRACT Unclassified

\begin{tabular}{|c|c|}
\hline & $\begin{array}{c}\text { 15. NUMBER OF PAGES } \\
18 \\
\end{array}$ \\
\hline ng & $\begin{array}{r}\text { 16. PAICE CODE } \\
\mathrm{AO} 3 \\
\end{array}$ \\
\hline $\begin{array}{l}\text { 19. SECUAITY CLASSIFICATION } \\
\text { OF ABSTRACT } \\
\text { Unclassified }\end{array}$ & 20. LIMTAATION OF ABSTRACT \\
\hline
\end{tabular}

